\title{
A Study of the Effect of Contrasting Colors on Improving the Memorization of English Vocabulary
}

\author{
Rain Chen ${ }^{1, *} \&$ Min Wang ${ }^{2}$ \\ ${ }^{1}$ Department of Visual Communication Design, Southern Taiwan University of Science and Technology, Taiwan, \\ R.O.C. \\ ${ }^{2}$ Master Program of Industrial Design, National Cheng Kung University, Taiwan, R.O.C. \\ *Correspondence: Department of Visual Communication Design, Southern Taiwan University of Science and \\ Technology, Taiwan, R.O.C. E-mail: ocean@stust.edu.tw
}

Received: September 8, 2020

Accepted: December 3, 2020 Online Published: February 2, 2021

doi:10.5430/jct.v10n1p1

URL: https://doi.org/10.5430/jct.v10n1p1

\begin{abstract}
This study was to investigate if three attributes of color, have a positive effect on improving the memorization of English vocabulary. Experimental design was adopted in the study, and there were 126 adults participating in the experiment. Among the participants, $26.2 \%$ were males and $73.8 \%$ were females, and the average age was 21 years old. In the experiment, participants were tested on memorizing English vocabulary under the influence of three color attributes. The results indicated that there were significant differences among different combinations of color attributes regarding the memorization of English vocabulary, and in the combinations, contrast of hue outperformed two other color attributes. In terms of subjective preference, contrast of value was participants' favorite on the average.
\end{abstract}

Keywords: contrast of hue, contrast of value, contrast of chroma, English vocabulary, memorization performance

\section{Introduction}

Colors and forms are main factors in constituting visual elements, and humans "vision is far more sensitive to colors than to shapes (Lin, 1989). Visual imagery is composed of various color lumps with combinations of different values and chromas. Contour line that defines shapes is interpreted through eyes' discrimination between values and areas. Colors are the fastest and directest stimulation for humans' vision, and moods and feelings are then influenced accordingly (Arnheim, 1982).

The percentages that humans intake information through five senses are: $87 \%$ sight, $7 \%$ hearing, $3 \%$ touch, $2 \%$ smell, and $1 \%$ taste (Huang, 2003). Sight is the most important one among all senses. Humans' perception of color is the visual representation built by information exchange through light, object, brain and eyes (Wertenbaker, 1909). There are three types of photoreceptor cells in the retina of human eyes. Cone cell is one of the three, and another one is rod cells for seeing black and white. Central fovea is located in the center of retina, with the highest visual sensitivity (Wegman \& Said, 2011).

Human beings can perceive wavelengths up to $810 \mathrm{~mm}$ visible light. The longer wavelength, the redder the visible light color; the shorter wavelength, the more violet the visible light color. The visual stimulation of almost any object can influence two cone cells at the same time so that human eyes can have high color perception and visual acuity (Wertenbaker, 1909).

From an objective perspective, colors are one of the external stimulation of light, but from a subjective perspective, colors are one of important psychological responses. When colors stimulate a person's brain, it leads to this person's emotional changes and affects the connection between memories or knowledges. Some scholars believed that colors are the basis for perception, and that is based on testees' experiences (Burchett, 1991). Some other scholars pointed out that people's visual preferences have a significant relationship with their life experiences and living environments in the past. Everyone has different interpretations and descriptions of colors on account of his background, religious 
belief, and culture (Balling et al., 1982).

In some studies of the relationship between color and memory, response time to colored pictures in naming tasks was shorter than that to pictures without colors (Price \& Humphreys, 1989; Wurm et al., 1993). When an object was displayed in a non-cognitive color (for example, the color of a red brick is displayed in blue), matching process in the human brain could be influenced by the color (Adams, 1923; Bruner et al., 1951; Duncker, 1939; Harper, 1953). As to a highly familiar object, the memory color could enhance the object's color features which are more saturate and brighter than the actual color (Bartleson, 1960; Newhall et al., 1957; Pe'rez-Carpinell et al., 1998). People might prefer an image with memory color and with the influence of the familiar object to the image's actual chroma (Yendrikhovskij et al., 1999). If the image color was close to the long-term memory color of people's subjective perception, people might believe that image has better quality (Bodrogi \& Tarczali, 2001). Some research results have showed that whether it is a familiar stimulus such as a word or an unfamiliar stimulus such as irregular lines, it can establish a memory in connection with colors. It proved that colors are main factor in discriminating objects, and colors can be stored in memory (Musen \& O'Neill, 1997).

Good color matching and application can help create brand value and brand differences. Some researches findings have demonstrated that brands with warm colors can spark excitement (Greald et al., 1997; Labrecque et al., 2011). Packaging design in green color could evoke consumers' eco-perception or health awareness, and red packaging could trigger people's autonomic nervous system's and cardiovascular system's response and then influence consumption decision (Christopher, 2008; Bagchi \& Cheema, 2013). In addition to applying colors to behavior, many researches have also attested that colors have a significant effect on perception. For example, red could induce higher levels of aggressive behavior. In the Olympic Games, a sports team in red clothing had a good chance of winning the competition (Hill \& Barton, 2005). The grip strength that male undergraduates have was stronger when they saw red stimulus as compared with green stimulus (O'Connell et al., 1985). People with Alzheimer's disease are usually weak at color differentiation and are emaciated. When different colors were applied to eating utensils, it was found significant that patients with severe Alzheimer's disease eat more and gain weight (Volicer \& Rheaume, 1994).

In the field of product design, marketing application, or even medical operation, color scheme is worth investigating. The application of colors does not hinge on a designer's personal preference. Experiments with colors must be carried out for further investigation. Since English learning has been in great demand in Asian countries, it is expected that the results of this study of how colors effect the memorization of English vocabulary can be applied in future English vocabulary textbooks and help improve students' learning outcomes in English.

\section{Method}

\subsection{Examinees}

There were 126 examinees $(26.2 \%$ females, $73.8 \%$ males $)$. This study intended to investigate the memorization performance of English vocabulary under the influence of different combinations of color attributes so participants in the experiment must have normal vision (before or after vision correction) and normal color vision. Before the experiment, the examiner explained the purpose and procedures of the experiment and made sure that all examinees understand and agree with the statements before conducting the experiment.

\subsection{Sample}

This study aimed to investigate the effect of three color attributes, "hue," "value," and "chroma," on the memorization performance of English vocabulary. The sampling was based on General English Proficiency Test (GEPT). The GEPT is solely administered by The Language Training \& Testing Center (LTTC). The test was first administered in Taiwan in 2000, and there are five levels of the test: elementary, intermediate, high-intermediate, advanced, and superior. The test suited the needs of English learners for self-assessment and provided institutions or schools with a reference for evaluating the English proficiency levels of their job applicants, employees, or students (Lee \& Wu, 2016). Since the superior level had been administered only once and then suspended, it was excluded from the experiment.

The passing rates of each GEPT level in 2015 decreased substantially as shown in Table 1. In the study, it was expected to select English words that examinees were unfamiliar with as the sample in the experiment to test their memorization performance. Therefore, the study took a sample of English vocabularies in the GEPT high-intermediate level. A scholar has noted the magic number seven plus or minus two in the experiment on the capacity for number memory, and which implied that the limit on short-term memory capacity is seven plus or minus two elements (Miller, 1956). These elements can be non-relevant letters, numbers, pictures, phrases, or sentences. On 
the basis of this principle, 9 words that fit the standard of high-intermediate level and seven plus or minus two were selected. Then they were randomly divided into three groups as the vocabularies for color matching using hue, value, and chroma respectively, and each color matching employed three words as its experimental sample.

Table 1. The Passing Rates of the GEPT in 2015

\begin{tabular}{|c|c|c|c|c|c|}
\hline Stages & Items & Elementary & Intermediate & High-Intermediate & Advanced \\
\hline \multirow[t]{3}{*}{ First stage } & Hearing & 82.34 & 82.82 & 79.7 & 73.61 \\
\hline & Reading & 79.94 & 75.28 & 79.84 & 65.07 \\
\hline & Passing rate & $51 \%$ & $44 \%$ & $48 \%$ & $41 \%$ \\
\hline \multirow[t]{3}{*}{ Second stage } & Writing & 3.8 & 3.5 & 3.5 & 2.3 \\
\hline & Speaking & 3.7 & 3.6 & 3.6 & 2.8 \\
\hline & Passing rate & $53 \%$ & $32 \%$ & $27 \%$ & $20 \%$ \\
\hline \multicolumn{2}{|c|}{ Average passing rate } & $52 \%$ & $38 \%$ & $38 \%$ & $31 \%$ \\
\hline
\end{tabular}

Concerning the effect of target color and background color on display result, the review of literatures implied that dark background color with light target color appears to be the best display (Bruce \& Foster, 1982; Mahnke \& Mahnke, 1987). Hence, the background color was dark and English words as the target were light in the experimental sample in the study. Table 2 shows RGB values to hue, value (lightness), and chroma in the experiment.

Table 2. RGB Values to Hue, Value (Lightness), and Chroma

\begin{tabular}{lllllll}
\hline & Word & \multicolumn{5}{c}{ Background } \\
\cline { 2 - 7 } Item & $\mathrm{R}$ & $\mathrm{G}$ & $\mathrm{B}$ & $\mathrm{R}$ & $\mathrm{G}$ & $\mathrm{B}$ \\
\hline Hue & 255 & 192 & 0 & 0 & 0 & 102 \\
Value & 255 & 255 & 255 & 38 & 38 & 38 \\
Chroma & 230 & 108 & 125 & 255 & 0 & 102 \\
\hline
\end{tabular}

\subsection{Design of Experiment}

There were two stages in the experiment. The first stage was instantaneous memory test, and the second stage was short term memory test. In the first stage, examinees were to memorize each word per 30 seconds, and then the test results in the second stage were to be the assessment indicators of memorization performance.

Before the experiment began, examiner explained to examinees the purpose and procedures of the experiment and what examinees have to do. The experiment commenced after the examiner made sure that all examinees had understood and agreed to follow the instructions.

In the first stage of instantaneous memory test, there were nine slides to play for the examinees. On each slide, there were an English word and its Chinese translation. Chinese translation was for examinees' understanding only. What examinees had to do was to write down the English word that was seen on an answer sheet. During the experiment, each English word were displayed for 30 seconds, and then examinees had 15 seconds to write down the English word on the answer sheet. After 15 seconds, the next English word were displayed for another 30 seconds. The first stage proceeded with repeated procedures until 9 English words were displayed and answered.

After all answered sheets were turned in, the examiner handed out the second stage test papers. The test paper provided the first letter, the last letter, and Chinese translation of each English word. Examinees wrote down all 9 English words by recalling what they had seen in the first stage. After that, examinees had to write down their answers to a question: if they were familiar with each word before the experiment? Their answers were taken into consideration whether any of the English words should be removed from the follow-up statistics. Hence, the test results in the second stage were the major statistical data in the study. Experiment scenes are shown in Figure 1. 


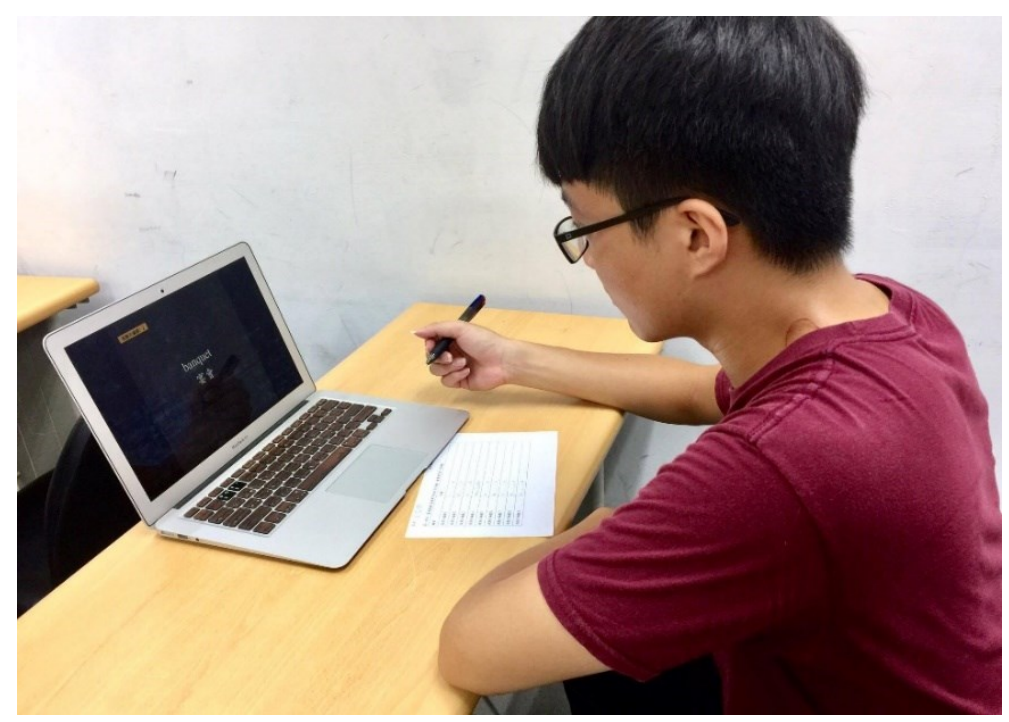

Figure 1. Experiment Scenes

Another aim of the experiment was to investigate if personal feeling had an effect on memorization performance. Subjective scoring was conducted to assess the criteria "visibility," "visual comfort," and "satisfaction" of three color matching combinations (contrast of hue, contrast of value, and contrast of chroma) by the examinees' giving scores to each criterion. In the study, visibility referred to a measure of how well an examinee could discriminate a word or symbol from the background, visual comfort referred to a measure of how comfortable an examinee felt or looked at a combination at that moment, and satisfaction referred to a measure of personal preference for a combination. The examinees wrote down their preferred hue, value, and chroma. Among the attributes, the selection of hue was based on Johannes Itten's 12-hue color circle (Johannes, 1973).

\subsection{Experimental Tool}

The experimental sample in the study was English vocabulary. Sample setting: laid out slide dimensions to be 25.4 $\mathrm{cm}$ wide x $25.4 \mathrm{~cm}$ high, used Times New Roman font, 60 point for English words and DFKai-SB font, 60 point for Chinese translation, and centered text. Samples of three color matching combinations are shown as Figure 2. Masked slides among color matching combinations were light gray for examinees to rest their eyes without interference from colors. To lower examinees' expectations and learning effect, three color matching combinations were displayed randomly, and same color matching attributes were not displayed successively.

\subsection{Statistical Methods}

After the experiment was finished, examinees' answer sheets were returned for data analysis. The study used SPSS Statistics to run ANOVA in order to determine whether there were significant differences between each color matching and the memorization performance of English vocabulary. In the analysis, hue, value, and chroma were independent variables, and dependent variables were the number of correct answers written by examinees. The study also adopted Chi-square test to analyze the relationship between gender and color preference. Finally, correlation analysis was employed to measure the strength of association that memorization performance had with visibility, visual comfort, and satisfaction. 
Hue

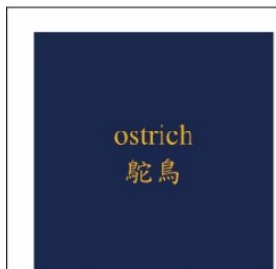

Sample 1

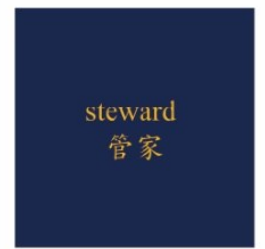

Sample 2

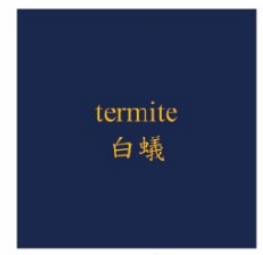

Sample 3
Value

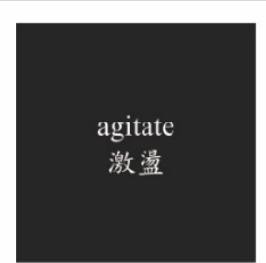

Sample 4

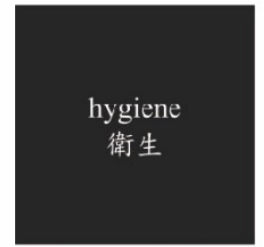

Sample 5

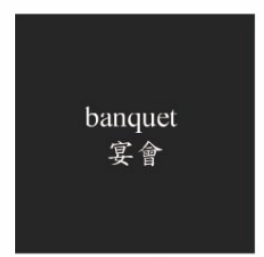

Sample 6

\section{Chroma}

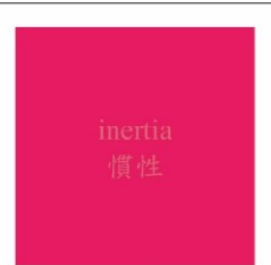

Sample 7

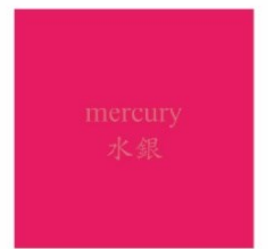

Sample 8

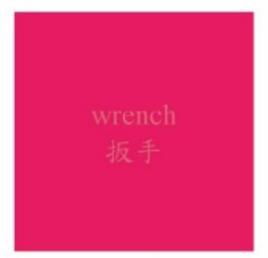

Sample 9

Figure 2. Samples of Three Color Matching Combinations

\section{Results}

\subsection{Descriptive Statistics}

This study attempted to evaluate the effect of three color matching attributes on the memorization performance of English vocabulary through experimental design. There were 126 adult participants $(26.2 \%$ males and $73.8 \%$ females), with an average age of 21. Participants' basic information is shown in Table 3.

Table 3. Participants' Basic Information

\begin{tabular}{lllll}
\hline Items & Variables & Number of respondents & Percentage & Rank \\
\hline \multirow{2}{*}{ Gender } & Female & 93 & $73.8 \%$ & 1 \\
& Male & 33 & $26.2 \%$ & 2 \\
& Under 21 & 74 & $58.7 \%$ & 1 \\
Age & $21 \sim 25$ & 49 & $38.9 \%$ & 2 \\
& $26 \sim 30$ & 1 & $0.8 \%$ & 3 \\
& $31 \sim 35$ & 1 & $0.8 \%$ & 3 \\
& $36 \sim 40$ & 0 & $0 \%$ & None \\
\hline
\end{tabular}

In the investigation of subjective preference for color matching attributes, the study used visibility, visual comfort, and satisfaction as criteria. 5 point Likert scale was adopted: $0=$ strongly disagree, $1=$ disagree, $2=$ neutral, $3=$ agree, $4=$ strongly agree. The analysis results, shown in Figure 3 , suggested that contrast of value was superior than two other color matching attributes; then contrast of hue was better than contrast of chroma. 


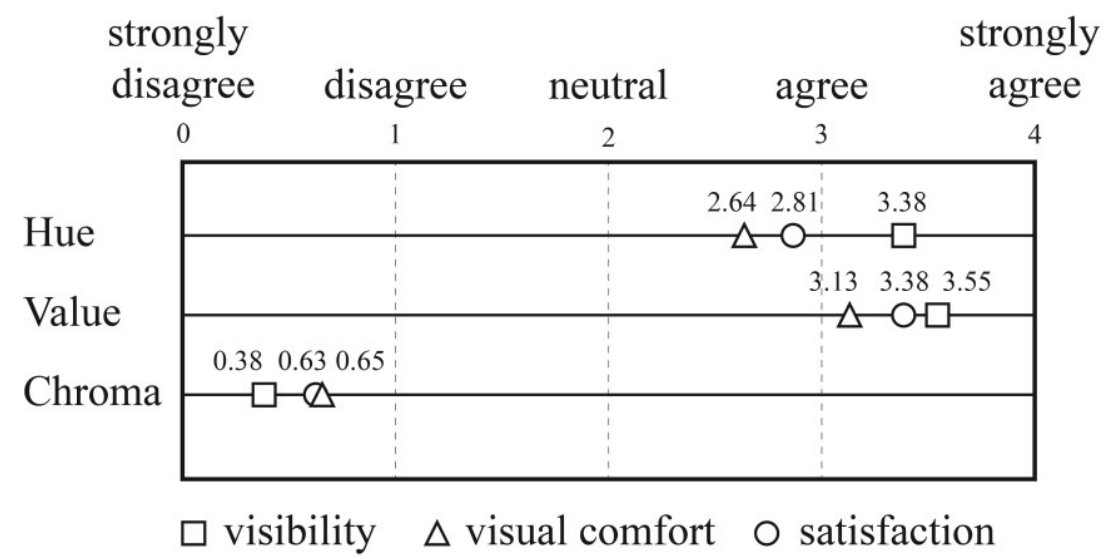

Figure 3. Subjective Preference for Three Color Matching Attributes

In the investigation of color preference shown in Table 4, 126 participants favored hue number $10(23 \%)$, medium value $(59.5 \%)$, and medium chroma (44.4\%).

Table 4. Examinees' Color Preference

\begin{tabular}{lllll}
\hline Color Attribute & Variables & Number of respondents & Percentage & Rank \\
\hline Hue & Number 10 & 29 & $23 \%$ & 1 \\
& Number 2 & 18 & $14.3 \%$ & 2 \\
& Number 3 & 17 & $13.5 \%$ & 3 \\
& Number 12 & 14 & $11.1 \%$ & 4 \\
& Number 9 & 13 & $10.3 \%$ & 5 \\
& Number 1 & 11 & $8.7 \%$ & 6 \\
Number 5 & 11 & $8.7 \%$ & 7 \\
Value & Number 7 & 5 & $4.0 \%$ & 8 \\
& Number 4 & 3 & $2.4 \%$ & 9 \\
& Number 11 & 3 & $2.4 \%$ & 10 \\
& Number 6 & 2 & $1.6 \%$ & 12 \\
Chroma & Number 8 & 0 & $0 \%$ & 1 \\
& Medium & 75 & $59.5 \%$ & 2 \\
& High & 39 & $31 \%$ & 3 \\
& Low & 12 & $9.5 \%$ & 1 \\
& Medium & 56 & $44.4 \%$ & 2 \\
\hline
\end{tabular}

\subsection{Analysis of Variance (ANOVA)}

The study conducted ANOVA to assess the effect of three color matching attributes on memorization of English vocabulary. Independent variables were hue, value, and chroma, and dependent variables were examinees' test results. Before statistical computations, English words that examinees were previously familiar with were removed. The ANOVA results revealed that there was significant difference $(p=0.000)$ between three color matching attributes and the memorization performance of English vocabulary. Scheffe's method was applied after the ANOVA, and its results verified that there was significant difference among hue, value, and chroma, but there was no significant difference between value and chroma $(p=0.731)$. The analysis results also manifested that the memorization performance of English vocabulary under the influence of contrast of hue was superior than the performance under the influence of contrast of value and contrast of chroma, as shown in Table 5. 
Table 5. Statistical Significance of Contrast of Hue, Contrast of Value, and Contrast of Chroma

\begin{tabular}{lllll}
\hline Dependent Variable & & Quantity & \\
\hline (I) Color & (J) Color & Mean Difference (I-J) & Std. Error & Sig. \\
\hline Hue & Value & 0.19071 & 0.04019 & 0.000 \\
\multirow{3}{*}{ Value } & Chroma & 0.15889 & 0.04019 & 0.000 \\
& Hue & -0.19071 & 0.04019 & 0.000 \\
Chroma & Chroma & -0.03183 & 0.04019 & 0.731 \\
& Hue & -0.15889 & 0.04019 & 0.000 \\
& Value & 0.03183 & 0.04019 & 0.731 \\
\hline
\end{tabular}

\subsection{Chi-Square Test}

This study performed Chi-square test to investigate the preference difference between genders and three color matching attributes. The finding indicated that there was no significant difference between genders and hue $(p=$ 0.231), meaning that no gender differences in the preference for hue; there was no significant difference between genders and value $(p=0.509)$, meaning that no gender differences in the preference for value; there was no significant difference between genders and chroma $(\mathrm{p}=0.913)$, meaning that no gender differences in the preference for chroma. On the whole, there were no gender differences in the preference for colors.

\subsection{Correlation Analysis}

Table 6 was the correlation analysis taken in the study to measure the relationship between test results and criteria of subjective preference. In the analysis, two of three criteria reached statistical significance. The Pearson correlation coefficient of memorization performance and visibility was 0.148 (the significance of the correlation coefficient computed in two-tailed test was 0.004), and the Pearson correlation coefficient of memorization performance and visual comfort was 0.108 (the significance of the correlation coefficient computed in two-tailed test was 0.036). Both of visibility and visual comfort had significant positive correlation with the memorization performance. From the analysis, the memorization performance had weak positive correlation with visibility and visual comfort, meaning that visibility and visual comfort have association with the memorization performance. In terms of correlation coefficient of all criteria, Pearson correlation coefficient of visibility and visual comfort was 0.796 (the significance of the correlation coefficient computed in two-tailed test was 0.000); Pearson correlation coefficient of visibility and satisfaction was 0.586 (the significance of the correlation coefficient computed in two-tailed test was 0.000); Pearson correlation coefficient of visual comfort and satisfaction was 0.631 (the significance of the correlation coefficient computed in two-tailed test was 0.000 ); the relationship among all criteria had reached significant level. As for the value of correlation coefficient, the correlation coefficient value of visibility and visual comfort was the highest, which meant these two criteria were strongly related; the relationship between visibility and satisfaction was moderate, and so was the relationship between visual comfort and satisfaction, as shown in Table 6 .

Table 6. Correlation Analysis of Memorization Performance of English Vocabulary and Contrast of Hue, Contrast of Value, and Contrast of Chroma

\begin{tabular}{llllllll}
\hline Variable & $\begin{array}{l}\text { Test } \\
\text { Result }\end{array}$ & $\begin{array}{l}\text { Sig. } \\
(2 \text {-tailed) }\end{array}$ & Visibility & $\begin{array}{l}\text { Sig. } \\
(2 \text {-tailed) }\end{array}$ & $\begin{array}{l}\text { Visual } \\
\text { Comfort }\end{array}$ & $\begin{array}{l}\text { Sig. } \\
\text { (2-tailed) }\end{array}$ & Satisfaction \\
\hline Test Result & 1 & -- & & & & & \\
Visibility & $0.148^{*}$ & 0.004 & 1 & & & & \\
Visual comfort & $0.108^{*}$ & 0.036 & $0.796^{*}$ & 0.000 & 1 & & \\
Satisfaction & 0.46 & 0.368 & $0.586^{*}$ & 0.000 & 0.631 & 0.000 & 2.28 \\
Mean & 1.056 & & 2.442 & & 2.146 & & 2.141 \\
Standard Deviation & 0.99 & & 1.636 & & 1.441 & & \\
\hline
\end{tabular}

\section{Discussion and Conclusion}

The purpose of this study was to investigate the effect of contrasting color matching on the memorization performance of English vocabulary. In 126 adult participants, $26.2 \%$ were males and $73.8 \%$ were females. The results of Chi-square test demonstrated that there are no gender differences in the preference for colors, and there are 
no significant differences in different genders' preference for hue, value, and chroma.

The experiment in the study proved that different color matching attributes had a significant influence on the memorization performance of English vocabulary. Contrast of hue had a greater influence on the memorization performance than contrast of value and contrast of chroma. As regards the evaluation of subjective preference for color matching, contrast of value received the highest average scores on visibility, visual comfort and chroma. The correlation analysis found that the memorization performance had significant positive correlation with visibility and visual comfort.

Overall statistical results manifested that although contrast of hue was not participants' favorite color matching combination, it helped improve the memorization performance compared with two other combinations. However, the experiment might be influenced by serial position effect so that the last word was the easiest to be remembered by examinees. Consequently, the memorization performance was improved, and the statistical results were affected. Serial position effect referred to the tendency of participants to recall the first and last few items in a series best (Baddeley, 1997).

In future study, it is suggested that the factor of serial position effect shall be considered in the experiment, and slides shall be played randomly. Moreover, examinees' age shall be normalized. In this study, only one combination was selected in each color matching attributes; therefore, the combination number of each color matching attributes can be increased in future study to enhance accuracy of the experiment and to further investigate what combination of color matching attributes most improves the memorization performance. It is hoped that the study findings can be applied in future English vocabulary textbooks and help students memorize English vocabulary.

\section{References}

Adams, G. K. (1923). An experimental study of memory color and related phenomena. The American Journal of Psychology, 34, 359-407. https://doi.org/10.2307/1413955

Arnheim, R. (1982). Art and Visual Perception. Taipei: Lion.

Baddeley, A. (1997). Human Memory: Theory and Practice. London, England: Psychology Press.

Bagchi, R., \& Cheema, A. (2013). The effect of red background color on willingness-to-pay: The moderating role of selling mechanism. Journal of Consumer Research, 39(5), 947-960. https://doi.org/10.1086/666466

Balling, J. D., \& Falk, J. (1982). Development of visual preference natural environments. Environment and Behavior, 14, 5-28. https://doi.org/10.1177/0013916582141001

Bartleson, C. J. (1960). Memory colors of familiar objects. Journal of the Optical Society of America, 50, 73-77. https://doi.org/10.1364/JOSA.50.000073

Bodrogi, P., \& Tarczali, T. (2001). Colour memory for various sky, skin, and plant colours: Effect of the image context. Color research and application, 26, 278-289. https://doi.org/10.1002/col.1034

Bruce, M., \& Foster, J. J. (1982). The Visibility of Colored Characters on Colored Background on View Data Displays. Visible Land, 32, 382-390.

Bruner, J. S., Postman, L., \& Rodrigues, J. (1951). Expectation and the perception of color. American Journal of Psychology, 64(2), 216-227. https://doi.org/10.2307/1418668

Burchett, E. K. (1991). Color harmony attribute. Color Research \& Application, 16(4), 275-278. https://doi.org/10.1002/col.5080160410

Christopher, J. P. (2008). Psychophysiological Correlates of Aggression and Violence: An Integrative Review. Philosophical Transactions of the Royal Society B: Biological Science, 363(1503), 2543-2555. https://doi.org/10.1098/rstb.2008.0028

Duncker, K. (1939). The influence of past experience upon perceptual properties. American Journal of Psychology, 52(2), 255-265. https://doi.org/10.2307/1416111

Greald, J. G., Chattopadhyay, A., Yi, T., \& Darren, W. D. (1997). Effects of Colors as an Executional Cue in Advertising: They're in the Shade. Management Science, 43(10), 1387-1400. https://doi.org/10.1287/mnsc.43.10.1387

Harper, R. S. (1953). The perceptual modification of colored figures. American Journal of Psychology, 66(1), 86-89. https://doi.org/10.2307/1417972 
Hill, R. A., \& Barton, R. A. (2005). Psychology: Red enhances human performance in contests. Nature, $435,293$. https://doi.org/10.1038/435293a

Huang, S. C. (2003). Basic of Chromatics. Taipei: Liu ho.

Johannes, I. (1973). The Art of Color: the subjective experience and objective rationale of color. New York: Van Nostrand Reinhold.

Labrecque, L. I., \& Milne, G. R. (2011). Exciting Red and Competent Blue: The Importance of Color in Marketing. Journal of the Academy of Marketing Science, 40(5), 711-727. https://doi.org/10.1007/s11747-010-0245-y

Lee, C., \& Wu, J. (2016). An Exploratory study on the relationships among student attitude towards the English graduation benchmark policy, learning motivation, test anxiety, and test performance. English Teaching \& Learning, 40(3), 61-86.

Lin, S. Y. (1989). Chromatics. Taipei: San Min.

Mahnke, F. H., \& Mahnke, R. H. (1987). Color and light in man-made environments. New York: Van Nostrand Reinhold.

Miller, G. A. (1956). The magical number seven, plus or minus two: Some limits on our capacity to processing information. Psychological Review, 63, 81-97. https://doi.org/10.1037/h0043158

Musen, G., \& O' Neill, J. E. (1997). Implicit memory for nonverbal associations. Journal of Experimental Psychology: Learning, Memory, and Cognition, 23, 1192-1202. https://doi.org/10.1037/0278-7393.23.5.1192

Newhall, S. M., Burnham R. W., \& Clark J. R. (1957). Comparison of successive with simultaneous color matching. Journal of the Optical Society of America, 47, 43-56. https://doi.org/10.1364/JOSA.47.000043

O'Connell, B. J., Harper, R. S., \& McAndrew, F. T. (1985). Grip strength as a function of exposure to red or green visual stimulation. Percept Mot Skills, 61(3), 1157-1158. https://doi.org/10.2466/pms.1985.61.3f.1157

Pe'rez-Carpinell, J., de Fez, M.D., Baldovi', R., \& Soriano J. C. (1998). Familiar objects and memory color. Color $\begin{array}{llll}\text { research and } \quad \text { aplication, } & \text { 23, }\end{array}$ https://doi.org/10.1002/(SICI)1520-6378(199812)23:6\%3C416::AID-COL10\%3E3.0.CO;2-N

Price, C. J., \& Humphreys, G. W. (1989). The effect of surface detail in object categorization and naming. Quarterly Journal of Experimental Psychology: Human Experimental Psychology, 41(4), 797-828. https://doi.org/10.1080/14640748908402394

Volicer, L., Rheaume, Y., \& Cyr, D. (1994). Treatment of depression in advanced Alzheimer's disease using sertraline. Geriatric Psychiatry and Neurology, 7(4), 227-229. https://doi.org/10.1177/089198879400700406

Wegman, E., \& Said, Y. (2011). Color theory and design. WIREs. https://doi.org/10.1002/wics.146

Wertenbaker, L. (1909). The Eye: Window to the World. New York.

Wurm, L. H., Legge, G. E., Isenberg, L. M., \& Luebker, A. (1993). Color improves object recognition in normal and low vision. Journal of Experimental Psychology: Human, Perception, and Performance, 19, 899-911. https://doi.org/10.1037/0096-1523.19.4.899

Yendrikhovskij, S. N., Blommaert, F. J. J., \& de Ridder, H. (1999). Color reproduction and the naturalness constraint. Color research and application, https://doi.org/10.1002/(SICI)1520-6378(199902)24:1\%3C52::AID-COL10\%3E3.0.CO;2-4

\section{Copyrights}

Copyright for this article is retained by the author(s), with first publication rights granted to the journal.

This is an open-access article distributed under the terms and conditions of the Creative Commons Attribution license (http://creativecommons.org/licenses/by/4.0/). 